\title{
MONOSOMY FOR 21pter-q21: CASE REPORT AND ASSIGNMENT OF A DNA CLONE (Fr8-77) TO THE DELETED SEGMENT
}

\author{
Kyohko ABe, ${ }^{1,2 *}$ Han-Xiang Deng, ${ }^{1}$ Naoki Harada, ${ }^{1,2}$ \\ Koh-ichiro Yoshiura, ${ }^{1}$ Takahiko OH-HIRA, ${ }^{3}$ and Norio NiIKawA ${ }^{1}$ \\ ${ }^{1}$ Department of Human Genetics, Nagasaki University School of Medicine, \\ Sakamoto-Machi, Nagasaki 852, Japan \\ ${ }^{2}$ Cytogenetics Research Laboratory, Kyushu Medical Science, \\ 9-9 Hamaguchi-machi, Nagasaki 852, Japan \\ ${ }^{3}$ Department of Pediatrics, Hitoyoshi City Hospital, \\ Hitoyoshi, Kumamoto 868, Japan
}

\begin{abstract}
Summary A 4-month-old Japanese girl with partial monosomy 21 was described. The patient has craniofacial anomalies, a short neck, wide-set nipples, anal atresia, deformed feet, hypertonia, intrauterine growth retardation, and mental deficiency. RFA- and high-resolution GTG-banding chromosome analyses, and Southern- and slot-blot analyses interpreted her karyotype as $45, \mathrm{XX},-2,-21,+\operatorname{der}(2) \mathrm{t}(2 ; 21)(\mathrm{q} 37.3 ; \mathrm{q} 22.1)$. The origin of this de novo translocation ascertained by analyses with both QFQheteromorphisms and a Fr8-77/BamHI RFLP was paternal. Comparison of the patient with previously reported patients confirmed that her manifestations are consistent with those of monosomy for 2.1pter-q21. Based on the results of molecular analyses on the present patient, a DNA clone, Fr8-77 (D21S82), was assigned to pter-q21.
\end{abstract}

Key Words monosomy 21, parental origin, regional mapping, locus D21S82

\section{INTRODUCTION}

There have been more than 40 cases of complete or partial monosomy 21 in the literature. Most cases among them are "pure" monosomy 21 in which only a

Received August 21, 1990; revised version received September 20, 1990; Accepted September 27, 1990.

This study was in part supported by a Grant-in-Aid for Scientific Research from the Ministry of Education, Science and Culture of Japan (No. 6?480472).

* Offprint requests to: Kyohko Abe, Department of Human Genetics, Nagasaki University School of Medicine, Sakamoto-Machi 12-4, Nagasaki 852, Japan. 
chromosome 21 is involved, or "almost pure" monosomy 21 as the result of translocation or insertion in which a negligible segment of the other chromosome is involved. When excluding cases of ring chromosome 21 and those of monosomy 21 due to translocation in which break points are ambiguous, 17 cases have been reported. Nine of the 17 cases had partial monosomy for the long-arm of chromosome 21 (Dutrillaux et al., 1973; David et al., 1977; Yamamoto et al., 1979; Modi and Buckton, 1982; Rivera et al., 1983; Wulfsberg et al., 1983; Yoshimitsu et al., 1983; Ferrante et al., 1983; Reynolds et al., 1985), and the remaining 8 patients were said to have complete monosomy 21 (Gripenberg et al., 1972; Halloran. et al., 1974; Dziuba et al., 1976; Fryns et al., 1977; Wisniewski et al., 1983; Herva et al., 1983; Pellissier et al., 1987; Garzicic et al., 1988). However, since complete monosomy 21 is extremely rare even among spontaneous abortuses and these abortuses present severe developmental defects (Ohama and Kajii, 1972; Kuliev et al., 1977), the existence of such newborn infants has remained doubtful (de Grouchy and Turleau, 1984).

We encountered a malformed infant with partial monosomy 21 who was first suspected as having complete monosomy 21 . We report herein the clinical manifestations of the patient and the results of cytogenetic and molecular studies.

\section{CLINICAL REPORT}

The patient, a 4-month-old Japanese girl, was born as a small-for-dates baby
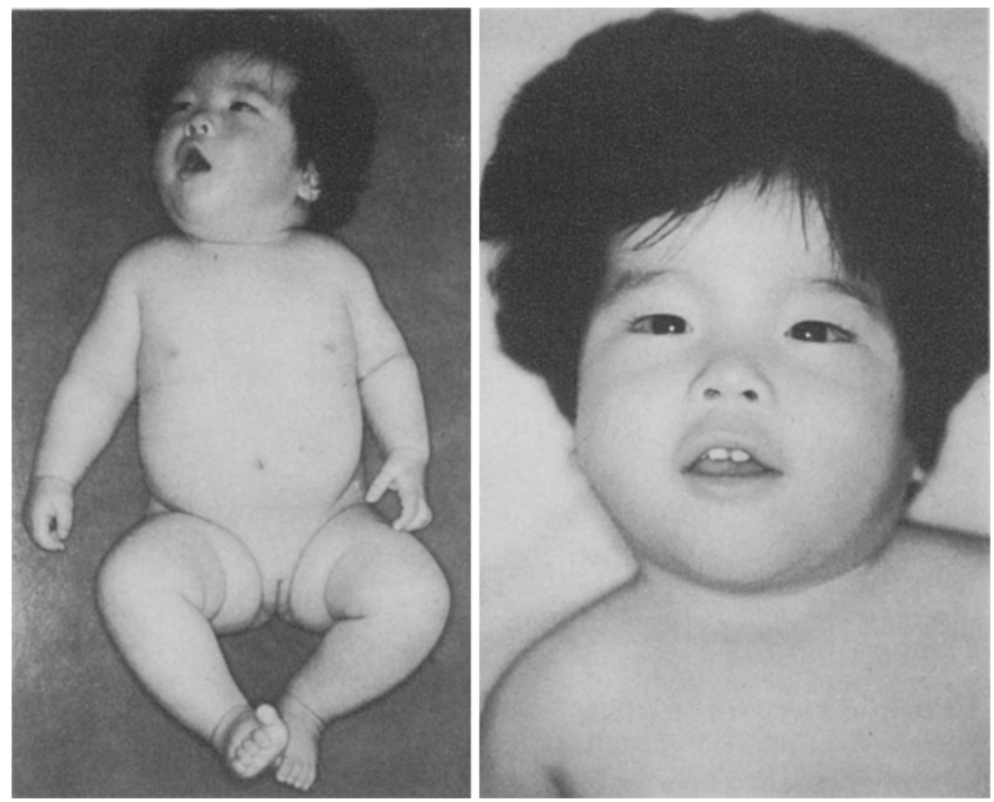

Fig. 1. Patient at age 4 months. 
at 39 weeks of gestation to a 30-year-old mother and a 33-year-old father. A 2year-old elder brother is healthy. The birth weight of the patient was $2,440 \mathrm{~g}$, length $44 \mathrm{~cm}$, head circumference (OFC) $32 \mathrm{~cm}$, and chest circumference $31 \mathrm{~cm}$. Anal atresia with a rectovaginal fistula was noticed immediately after birth and operated at age one month. She had dolichocephaly, down-slanting palpebral fissures, hypopigmented iris, a short nose with a low nasal-root and anteverted nostrils, a wide philtrum, the protruding maxilla, a short neck with a low posterior hair-line, wide-set nipples, ring-shaped skin-furrows at the wrist and the ankle, and pes varus (Fig. 1). Muscle tonus was increased and intention tremor was observed. The skin was hyperhidrotic. Growth and mental retardation was evident.

\section{CYTOGENETIC AND MOLECULAR STUDIES}

Chromosome analysis of the patient was performed on cultured peripheral blood lymphocytes and skin fibroblasts with conventional Giemsa staining, and GTG-, QFQ-, RFA- and high-resolution GTG-bandings. Karyotyping of her parents were done on their cultured lymphocytes.

Southern and/or slot blot analyses were performed using several DNA clones localized on chromosome 21 as probes to confirm the segment lost, or in turn to ascertain the loci of these clones precisely. Probes used for Southern analyses were pGSE9 (locus name: D21S16, localization: 21q21.2), pGSB3 (D21S19, 21q 22.3-qter) (provided by Dr. G.D. Stewart) and Fr8-77 (D21S82, 21pter-qter) (provided by Dr. G. Scherer), and those for slot blot analyses included p21-4U (D21S110, 21q11.2 or 21q21.2) (provided by Dr. D.M. Kurnit), FB68L [the amyloid beta (A4) precursor protein gene (APP), 2lq21.2] (provided by Dr. R.E. Tanzi), pGSE8 (D21S17, 21q22.3), pGSE9 (provided by Dr. G.D. Stewart), and Fr8-77 (Kidd et al., 1989). Genomic DNA was extracted from peripheral blood leukocytes or lymphoblastoid cell lines of the patient and her parents. Digestion of DNA with endonucleases, electrophoresis, Southern blotting, hybridization to probes, washing, and subsequent autoradiography were all done according to the standard methods. For slot blot analyses, $4 \mu \mathrm{g}$ DNA blotted onto a nylon membrane by the use of the microfiltration apparatus (Bio-Dot, Bio-Rad, USA) was hybridized with each of the ${ }^{32} \mathrm{P}$-labeled probes. The membrane was washed twice at room temperature for $15 \mathrm{~min}$ with $2 \times \mathrm{SSC}$ and $0.1 \% \mathrm{SDS}$, and twice each at $60^{\circ} \mathrm{C}$ for 15 min with $1 \times \mathrm{SSC}$ and with $0.1 \times \mathrm{SSC}$. It was then proceeded to autoradiography. Quantitative gene dose analyses were performed by densitometry on their respective autoradiographic signals comparing with the signal for an internal control [the parathyroid hormone $(\mathrm{PTH})$ gene localized at $11 \mathrm{p} 15.5$ or the argininosuccinate synthetase (ASS) gene at $9 q 34-q$ ter]. 


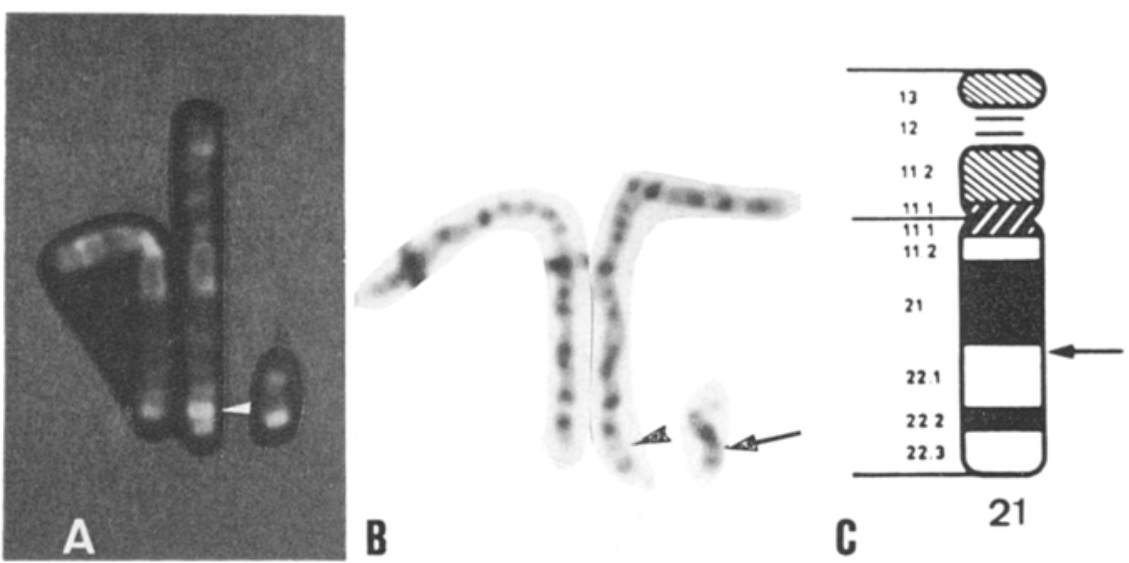

Fig. 2. RFA- (A) and high-resolution GTG-banded (B) chromosomes 2, der(2), and 21 of the patient, and idiogram of chromosome 21 (C). Arrows and arrow-heads indicate the break point and the rejoining point, respectively.

Table 1. Relative densities of autoradiographic bands for the 6 loci examined in the patieni.

\begin{tabular}{|c|c|c|c|c|c|c|}
\hline \multirow{2}{*}{ Gene name } & \multirow{2}{*}{ Probe } & \multicolumn{2}{|c|}{ Density a } & \multirow{2}{*}{$\begin{array}{l}\text { Estimated } \\
\text { copy } \\
\text { number }\end{array}$} & \multicolumn{2}{|c|}{ Localization } \\
\hline & & $\mathrm{Al}$ & A2 & & HGM10 & From our data \\
\hline $\mathrm{D} 21 \mathrm{~S} 110$ & $\mathrm{p} 2 \mathrm{l}-4 \mathrm{U}$ & 0.89 & & 1 & $\begin{array}{c}21 \mathrm{q} 11.2 \text { or } \\
21 \mathrm{q} 21.2\end{array}$ & \\
\hline D21S16 & pGSE9 & 1.03 & & 1 & $21 \mathrm{q} 21.2$ & \\
\hline APP & FB68L & 1.05 & & 1 & $21 q 21.2$ & \\
\hline D21S17 & pGSE8 & (1) & (1) & 2 & $21 \mathrm{q} 22.3$ & \\
\hline D21S19 & pGSB3 & (1) & (1) & 2 & 21q22.3-qter & \\
\hline D21S82 & Fr8-77 & (1) & - & 1 & 21 pter-qt $-\mathrm{r}$ & 21 pter-q21.3 \\
\hline
\end{tabular}

a A1 and A2 are larger and smaller polymorphic alleles in size, respectively. Copy numbers in parentheses were de tected by RFLP analyses. Other densities are average values calculated by the comparison with those in normal control individuals.

\section{RESULTS AND DISCUSSION}

Since a first routine analysis on 20 GTG-banded metaphases of the patient suggested monosomy 21 , a total of 200 cells from both lymphocytes and skin fibroblasts were counted and various banding analyses were performed to find mosaicism or translocation. Translocation of a small distal $21 \mathrm{q}$ segment to $2 \mathrm{q} 37.3$ was found with RFA-banding, and the break points were detected with high-resolution GTGbanding (Fig. 2). Thus, the karyotype of the patient was interpreted as $45, \mathrm{XX}$, $-2,-21,+\operatorname{der}(2) \mathrm{t}(2 ; 21)(\mathrm{q} 37.3 ; \mathrm{q} 22.1)$. The karyotypes of the parents were normal.

Densitometric analysis on polymorphic DNA fragments detected by Fr8-77/ 


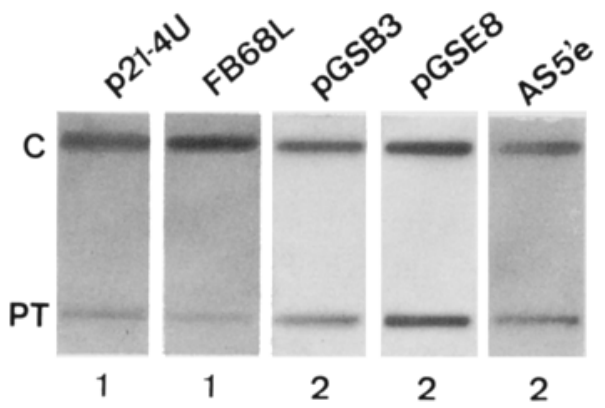

Fig. 3. Slot blots of the patient (PT) and a normal control individual (C). The $5^{\prime}$ end subclone (AS5'e) of the ASS gene is used as a control probe. Copy number of each DNA in the patient is shown at the bottom.
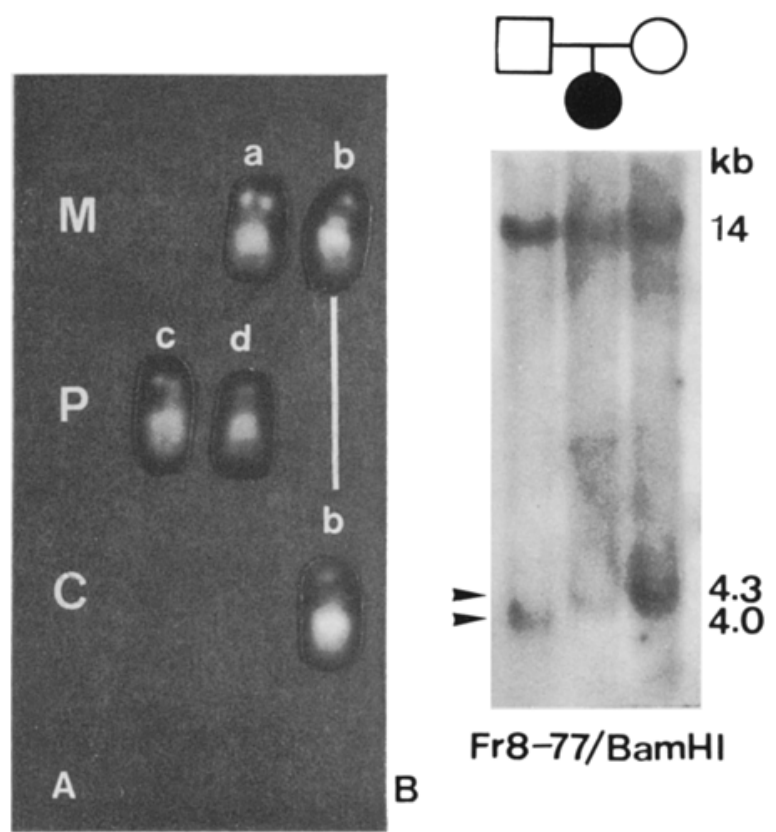

\section{Fr8-77/BamHI}

Fig. 4. Heteromorphisms of chromosomes 21 (A) and the Fr8-77/BamHI RFLP (B) in the patient and her parents. M, mother; $P$, father; $C$, patient; $a-d$, symbolized heteromorphic chromosomes 21. Arrow heads on Southern blots indicate polymorphic Fr8-77/BamHI fragments, and the $14 \mathrm{~kb}$ fragment is an internal control (the PTH gene).

BamHI (Kidd et al., 1989) interpreted the genotypes of the father, the mother, and the patient as $4.0 \mathrm{~kb} / 4.0 \mathrm{~kb}, 4.3 \mathrm{~kb} / 4.3 \mathrm{~kb}$, and $4.3 \mathrm{~kb} /-$, respectively (Table 1, Fig. 4b). Similar results were obtained in the analysis with pGSE9/XmnI and with pGSB3/PstI (Table 1). These findings indicated that the patient has one copy 
of DNA corresponding to each of these probes. Slot blot analyses showed that the patient has one copy each of the D21S110 and the APP gene, and two copies each of D21SD19 and D21S17 (Table 1, Fig. 3). The results supported the cytogenetic finding that the patient loses a 21 pter-q21 segment but retains two copies of the 21q22.1-qter segment.

The parental origin of the de novo translocation in the patient was traced using chromosome heteromorphisms and RFLPs as markers. When the patterns of QFQ-heteromorphic markers on the maternal and the paternal chromosomes 21 were symbolized as "a, b," and "c, d." respectively, the patient's chromosome 21 showed the "b" pattern (Fig. 4a), indicating that the translocation occurred at

Table 2. Comparison of manifestations among patients with monosomy 21 .

\begin{tabular}{|c|c|c|c|c|}
\hline \multirow{2}{*}{ Clinical manifestation } & \multirow{2}{*}{$\begin{array}{l}\text { Present } \\
\text { patient }\end{array}$} & \multicolumn{3}{|c|}{ Number of patients with monosomy for } \\
\hline & & 21 pter-q22 & 21q22-qter & 21 pter-qter \\
\hline Intrauterine growth retardation & + & $2 / 5$ & $3 / 4$ & $6 / 8$ \\
\hline Mental retardation & + & $4 / 5$ & $3 / 4$ & $4 / 8$ \\
\hline Hypertonia & + & $2 / 5$ & $2 / 4$ & $3 / 8$ \\
\hline Seizure & - & - & - & $2 / 8$ \\
\hline Failure to thrive & - & $1 / 5$ & $2 / 4$ & $5 / 8$ \\
\hline Microcephaly & - & $1 / 5$ & $1 / 4$ & $1 / 8$ \\
\hline Prominent forehead & + & - & $1 / 4$ & $1 / 8$ \\
\hline Low-set ear & + & $2 / 5$ & $1 / 4$ & $7 / 8$ \\
\hline Downslanting palpebral fissure & + & $2 / 5$ & $1 / 4$ & $7 / 8$ \\
\hline Prominent/broad nose & - & - & $3 / 4$ & $6 / 8$ \\
\hline High-arched/cleft palate & + & $2 / 5$ & - & $9 / 8$ \\
\hline Micrognathia & + & $1 / 5$ & $2 / 4$ & $7 / 8$ \\
\hline Short neck & + & $2 / 5$ & - & $3 / 8$ \\
\hline Low hair-line & + & - & - & $1 / 8$ \\
\hline Wide-set nipples & + & - & $2 / 4$ & $2 / 8$ \\
\hline Lung anomaly & - & - & $1 / 4$ & $1 / 8$ \\
\hline Heart anomaly/murmur & - & $2 / 5$ & $2 / 4$ & $4 / 8$ \\
\hline Anal anomaly & + & - & $1 / 4$ & $1 / 8$ \\
\hline Genital anomaly & + & $2 / 5$ & $1 / 4$ & $4 / 8$ \\
\hline Joint stiffness & + & $1 / 5$ & $1 / 4$ & $4 / 8$ \\
\hline Malposition of finger & - & $1 / 5$ & - & $2 / 8$ \\
\hline Club foot & + & - & - & $1 / 8$ \\
\hline Nail anomaly & - & - & $2 / 4$ & $1 / 8$ \\
\hline
\end{tabular}

$\div$, presence of feature; - , absence of feature or absence of reported cases with feature. Data are from the present case, Gripenberg et al. (1972), Dutrillaux et al. (1973), Halloran et al. (1974), Dziuba et al. (1976), David et al. (1977), Fryns et al. (1977), Yamamoto et al. (1979), Modi and Buckton (1982), Wulfsberg et al. (1983), Rivera et al. (1983), Yoshimitsu et al. (1983), Ferrante et al. (1983), Wisniewski et al. (1983), Herva et al. (1983), Reynolds et al. (1985), Pellissier et al. (1987), and Garzicic et al. (1988). 
the paternal meiosis. The result was confirmed by the RFLP study with Fr8-77, showing that the patient lacks a $4.0 \mathrm{~kb}$ BamHI fragment that should have been transmitted from her father (Fig. 4b).

Although eight patients with non-mosaic complete monosomy 21 have been reported, some clinical cytogeneticists doubted their karyotypes by reasons of less convincing results of banding analyses and a significant discrepancy of the phenotypes between the abortus and the live-born infant with this chromosome abnormality. The manifestations are usually very severe in abortuses (Ohama and Kajii, 1972; Kuliev et al., 1977), while those in live-born infants are rather compatible with life. In fact, with advanced techniques, re-evaluations of patients who had been diagnosed as complete monosomy 21 revealed the presence of a part of chromosome 21 (Ikeuchi et al., 1976; David et al., 1977; Phelan et al., 1988). We also first overlooked a small translocated $21 \mathrm{q}$ segment but confirmed its presence after the RFA-banding analysis as well as molecular studies. Although the manifestations in patients who were said to have complete monosomy 21 tend to be severer than those in patients with partial monosomy 21 , the difference may not be significant (Table 2). Therefore, it is likely that most cases of seemingly complete monosomy 21 retain a small chromosomal segment that may be involved in translocation or insertion.

The presence of a 21q22.1-qter segment in our patient was confirmed moleculargenetically. The result can in turn be used for regional assignment of the cloned DNAs. The probe, Fr8-77 (D21S82), was mapped on chromosome 21, but its regional localization has not yet been assigned. Since she has one copy of this DNA sequence, it must be located within the 21 pter-q21.3 segment.

Acknowledgments We express our gratitude to Dr. G.D. Stewart, Dr. G. Scherer, Dr. D.M. Kurnit, Dr. R.E. Tanzi and to American Type Culture Collection, for providing probes.

\section{REFERENCES}

David, K.K., Hsu, L.Y.F., Cristian, S. and Hirschhorn, K. 1977. "Monosomy" re-evaluated. Pediatr. Res, 11: 454.

de Grouchy, J. and Turleau, C. 1984. Chromosome 21. In Clinical Atlas of Human Chromosomes, 2nd Ed., John Wiley \& Sons, New York, pp. 336-359.

Dutrillaux, B., Jonasson, J., Lauren, K., Lejeune, J., Lindsten, J., Petersen, G.B. and Saldana-Garcia, P. 1973. An unbalanced $4 \mathrm{q} / 21 \mathrm{q}$ translocation identified by the $\mathrm{R}$ but not by the $\mathrm{G}$ and $\mathrm{Q}$ chromosome banding techniques. Ann. Génét. 16: 11-16.

Dziuba, P., Dziekanowska, D. and Hubner, H. 1976. A female infant with monosomy 21. Hum. Genet. 31: 351-353.

Ferrante, E., Vignetti, P., Antonelli, M., Bruni, L., Bertasi, S. and Chessa, L. 1983. Partial monosomy for a 21 chromosome. Helv. Paediatr. Acta 38: 73-80.

Fryns, J.P., D'Hondt, F., Goddeeris, P. and van den Berghe, H. 1977. Full monosomy 21: A clinically recognizable syndrome? Hum. Genet. 37: 155-159.

Garzicic, B., Guc-Scekic, M., Pilic-Radivojevic, G., Ignjatovic, M. and Vilhar, N. 1988. A case of monosomy 21. Ann. Génét. 31: 247-249. 
Gripenberg, U., Elfving, J. and Gripenberg, L. 1972. A 45,XX,21 - child: Attempt at a cytological and clinical interpretation of the karyotype. J. Med. Genet. 9: 110-115.

Halloran, K.H., Breg, W.R. and Mahoney, M.J. 1974. 21 monosomy in a retarded female infant. J. Med. Genet. 11: 386-389.

Herva, R., Koivisto, M. and Seppanen, U. 1983. 21-monosomy in a liveborn infant. Eur. $J$. Pediatr. 140: 57-59.

Ikeuchi, T., Kondo, I., Sasaki, M., Kaneko, Y., Kodama, S. and Hattori, T. 1976. Unbalanced 13q/21q translocation: A revised study of the case previously reported as 21-monosomy. Hum. Genet. 33: 327-330.

Kidd, K.K., Bowcock, A.M., Schmidtke, J., Track, R.K., Ricciuti, F., Hitchings, G., Bale, A., Pearson, P.L. and Willard, H.F. 1989. Report of the committee and catalogs of cloned and mapped genes and DNA ploymorphisms. Human Gene Mapping 10. New Haven Conderence (1989). Tenth International Workshop on Human Gene Mapping. Cytogenet. Cell Genet. 51: 622-947.

Kuliev, A.M., Gringerg, K.N., Kukharenko, V.I. and Kulazenko, V.P. 1977. Monosomy 21 in a human spontaneous abortus. Hum. Genet. 38: 137-145.

Modi, N. and Buckton, K.E. 1982. Interstitial deletion of chromosome 21. Clin. Genet, 22: 215-219.

Ohama, K. and Kajii, T. 1972. Monosomy 21 in spontaneous abortus. Humangenetik 16: 267270.

Pellissier, M.C., Philip, N., Voelckel-Baeteman, M.A., Mattei, M.G. and Mattei, J.F. 1987. Monosomy 21 : a new case confirmed by in situ hybridization. Hum. Genet. 75: 95-96.

Phelan, M.C., Morton, C.C., Stevenson, R.E., Tanzi, R.E., Stewart, G.D., Watkins, P.C., Gusella, J.F. and Amos, J.A. 1988. Molecular and cytogenetic characterization of de novo $\mathrm{t}(5 \mathrm{p} ; 21 \mathrm{q})$ in a patient previously diagnosed as monosomy 21. Am. J. Hum. Genet. 43: 511-519.

Reynold, J.F., Wyandt, H.E. and Kelly, T.E. 1985. De nova $21 \mathrm{q}$ interstitial deletion in a retarded boy with ulno-fibular dysostosis. Am. J. Med. Genet. 20: 173-180.

Rivera, H., Rivas, F., Plascencia, L. and Cantu, J.M. 1983. <Pure > monosomy 2lpter-q21 in a girl born to a couple $46, \mathrm{XX}, \mathrm{t}(14 ; 2 \mathrm{I})(\mathrm{p} 12 ; \mathrm{q} 22)$ and $46, \mathrm{XY}, \mathrm{t}(5 ; 18)(\mathrm{q} 32 ; \mathrm{q} 22)$. Ann. Génét. 26: 234-237.

Wisniewski, K., Dambska, M., Jenkins, E.C., Sklower, S. and Brown, W.T. 1983. Monosomy 21 syndrome: Further delineation including clinical, neuropathological, cytogenetic and biochemical studies. Clin. Genet. 23: 102-110.

Wulfsberg, E.A., Carrel, R.E., Klisak, I.J., O'Brien, T.J., Sykes, J.A. and Saprkes, R.S. 1983. Normal superoxide dismutase-1 (SOD-1) activity with deletion of chromosome band 21q21 supports localization of SOD-1 locus to 21q22. Hum. Genet. 64: 271.

Yamamoto, Y., Ogasawara, N., Gotoh, A., Komiya, H., Nakai, H. and Kuroki, Y. 1979. A case of $21 \mathrm{q}$ - syndrome with normal SOD-1 activity. Hum. Genet. 48: 321-327.

Yoshimitsu, K., Hatano, S., Kobayashi, Y., Takeoka, Y., Hayashidani, M., Ueda, K., Nomura, K., Ohama, K. and Usui, T. 1983. A case of $21 \mathrm{q}-$ syndrome with half normal SOD-1 activity. Hum. Genet. 64: 200-202. 